Citation: Korkmaz, M., "A Study on The Application of Lagrange Interpolation to the Estimations of Gas Production Based Over Time". Journal of Engineering Technology and Applied Sciences 5 (2) 2020 : 65-75.

\title{
A STUDY ON THE APPLICATION OF LAGRANGE INTERPOLATION TO THE ESTIMATIONS OF GAS PRODUCTION BASED OVER TIME
}

\author{
Mehmet Korkmaz \\ Department of Mathematics, Ordu University, Turkey \\ mkorkmaz52@yahoo.com
}

\begin{abstract}
In this study, Lagrange interpolation which could be an alternative modeling passing throughout exactly all data points with respect to linear or nonlinear models was applied to the experimental data, the findings of gas production based over time. After getting Lagrange interpolation, extremum points, turning points (if exists) could be found. Also for some intermediate level, its estimated values could be found. Furthermore, for a desired result value, its intermediate level could be estimated. The graphs of Lagrange interpolation were given. The standard errors with confidence level 95\% of the values mentioned above could be estimated by using Lagrange interpolation technique. The graphs of standard errors were given. In addition, missing data values can be estimated and compared with observation value.
\end{abstract}

Keywords: Lagrange interpolation, experimental data

\section{Introduction}

In this study, Lagrange interpolation, alternative modeling passing to exactly all data points with respect to linear or nonlinear models applied to experimental data will be used.

The reason for using Lagrange interpolation is that it is quite successful for estimating and easy to compute for researchers since Lagrange interpolation is a polynomial function [1]. So it is useful to use instead of more general and complicated functions which do not pass exactly through all data points [2].

In this study, the Lagrange interpolation approach is applied to a real research data. This way, the new information that can be added to the results of the analysis obtained by classical and commonly used statistical methods are presented $[3,4,5]$. 
Conventional methods cannot be applied to obtain such information as the result values of any intermediate levels, the absolute and local extremum points, turning point, a desired outcome at any level or intermediate level, the standard errors of all estimated values. This information used by researchers to support traditional statistical analysis, strengthen quality is thought to be useful as additional information [6].

The result values of any intermediate levels or outside the range levels which could not get in the experiment in addition to the intermediate level of a desired result value, the absolute and local extremum points, turning points and missing observations could be estimated with Lagrange interpolation technique. In addition, the researcher can estimate the standard errors and confidence limits of the obtained estimates by using Lagrange interpolation technique and then can obtain the interaction graphs which connect the average points [7].

\section{Material and methods}

\subsection{Material}

Time-dependent in vitro gas production values of harvest times belonging to Trifolium repens, one of legume forage plants were used. Harvest time is vegetative, flowering and seeding stages. Time-dependent average in vitro gas production amounts are made in 3,6,12,24,48,72 and 96 hour periods in Table 1[8].

Table 1. According to certain clock levels, time-dependent in vitro gas production values of harvest times belonging to Trifolium repens

\begin{tabular}{|c|l|l|l|}
\hline \multicolumn{4}{|c|}{ in vitro Gas Production (ml/1 g DM) } \\
\hline & \multicolumn{3}{|c|}{ Harvest Time } \\
\hline Hour & Vegetative & Flowering & Seeding Stages \\
\hline 3 & 137.50 & 116.67 & 113.33 \\
\hline 6 & 189.17 & 175.83 & 169.17 \\
\hline 12 & 241.67 & 221.67 & 216.17 \\
\hline 24 & 306.67 & 286.67 & 271.67 \\
\hline 48 & 350.83 & 340.83 & 326.67 \\
\hline 72 & 390.83 & 373.33 & 358.33 \\
\hline 96 & 407.50 & 385.00 & 371.83 \\
\hline DM: Dry Matter \\
\hline
\end{tabular}

\subsection{Methods}

\section{Lagrange interpolation}

There is the interpolation polynomial $P_{n}(x)$ according to $x_{0}, x_{1}, x_{2}, \ldots, x_{n}$ providing the conditions

$a_{0}+a_{1} x_{i}+a_{2} x_{i}^{2}+\ldots+a_{n} x_{i}^{n}=f\left(x_{i}\right)=P_{n}\left(x_{i}\right), i=0,1,2, \ldots, n$

given $n+1$ corresponding points $f\left(x_{0}\right), f\left(x_{1}\right), f\left(x_{2}\right), \ldots, f\left(x_{n}\right)$ for $x_{0}, x_{1}, x_{2}, \ldots, x_{n}$ in the range of $[a, b]$ where $\mathrm{n}$ is the degree of the polynomial, $a$ is the initial value, $\mathrm{b}$ is the end value and 
$a_{0}, a_{1}, \ldots, a_{n}$ are the coefficient of the polynomial. There is only one polynomial $P_{n}(x)$ which degree is not greater than $\mathrm{n}[9,10]$.

The most important and practical method obtaining polynomial interpolation without solving Equation (1) is Lagrange interpolation. This method does not need to be in the range of the data [11].

$\mathrm{n}^{\text {th }}$ degree Lagrange interpolation polynomial for $\mathrm{n}+1$ data points $\left(x_{i}, y_{i}\right), i=0,1,2, \ldots, n$ can be obtained as follows.

$$
f(x)=y=\sum_{i=0}^{n} y_{i} \prod_{\substack{j=0 \\ j \neq i}}^{n} \frac{x-x_{j}}{x_{i}-x_{j}}
$$

\section{Continuity of Lagrange interpolation}

Lagrange interpolation function is continuous because it is a polynomial function. As known if a function is continuous, then it's intermediate values can be found.

\section{Results and discussion}

In this study the dark-colored numbers and the light-colored numbers in the tables show the observation values and the estimated values, respectively.

Interpolation techniques are aimed to reach additional information. Instead of applying direct interpolation to above table (Table 1), it has been considered appropriate to estimate using logarithmic interpolation.

Intermediate levels with extremum and their gas production estimates obtained by Lagrange interpolation on the data of Table 1 are given in Table 2.

Table 2 shows the intermediate levels with extremum that can be obtained for each level of harvest time factor (Vegetative, Flowering, Seeding Stages) and their estimated average gas production. For example, an extremum point was estimated for vegetative harvest time at 94.32 hours and its value was found to be $407.61 \mathrm{ml} / 1 \mathrm{~g}$ DM.

Table 2. Intermediate levels with extremum and their gas production estimates (ml/1 g DM)

\begin{tabular}{|l|l|l|l|}
\hline \multicolumn{4}{|c|}{ in vitro Gas Production (ml/1 g DM) } \\
\hline & \multicolumn{3}{|c|}{ Harvest Times } \\
\hline Hour & Vegetative & Flowering & Seeding Stages \\
\hline 3 & 137.50 & 116.67 & 113.33 \\
\hline 6 & 189.17 & 175.83 & 169.17 \\
\hline 12 & 241.67 & 221.67 & 216.17 \\
\hline 24 & 306.67 & 286.67 & 271.67 \\
\hline 48 & 350.83 & 340.83 & 326.67 \\
\hline 72 & 390.83 & 373.33 & 358.33 \\
\hline 94.32 & 407.61 & & \\
\hline 94.69 & & 385.04 & \\
\hline 96 & 407.50 & 385.00 & 371.83 \\
\hline 101.33 & & & 372.30 \\
\hline
\end{tabular}


Table 3 shows the intermediate levels with turning point that can be obtained for each level of harvest time factor (Vegetative, Flowering, Seeding Stages) and their estimated average gas production. For example, a turning point was estimated for vegetative harvest time at 5.04 hours and its value was found to be $186.58 \mathrm{ml} / 1 \mathrm{~g}$ DM.

Table 3. Intermediate levels with turning points and their gas production estimates (ml/1 g DM)

\begin{tabular}{|l|l|l|l|}
\hline \multicolumn{5}{|c|}{ in vitro Gas Production (ml/1 g DM) } \\
\hline & \multicolumn{3}{|c|}{ Harvest Times } \\
\hline Hour & Vegetative & Flowering & Seeding Stages \\
\hline $\mathbf{3}$ & $\mathbf{1 3 7 . 5 0}$ & $\mathbf{1 1 6 . 6 7}$ & $\mathbf{1 1 3 . 3 3}$ \\
\hline 5.04 & 186.58 & & \\
\hline 5.36 & & 172.34 & \\
\hline 5.52 & & & 164.41 \\
\hline $\mathbf{6}$ & $\mathbf{1 8 9 . 1 7}$ & $\mathbf{1 7 5 . 8 3}$ & $\mathbf{1 6 9 . 1 7}$ \\
\hline $\mathbf{1 2}$ & $\mathbf{2 4 1 . 6 7}$ & $\mathbf{2 2 1 . 6 7}$ & $\mathbf{2 1 6 . 1 7}$ \\
\hline 12.54 & 246.56 & & \\
\hline 14.59 & & 240.56 & \\
\hline 15.68 & & & 237.92 \\
\hline $\mathbf{2 4}$ & $\mathbf{3 0 6 . 6 7}$ & $\mathbf{2 8 6 . 6 7}$ & $\mathbf{2 7 1 . 6 7}$ \\
\hline 27.14 & & & 281.27 \\
\hline 31.19 & 322.34 & & \\
\hline 34.89 & & 316.09 & $\mathbf{3 2 6 . 6 7}$ \\
\hline $\mathbf{4 8}$ & $\mathbf{3 5 0 . 8 3}$ & $\mathbf{3 4 0 . 8 3}$ & 328.88 \\
\hline 49.32 & & & \\
\hline 56.26 & & 353.82 & $\mathbf{3 5 8 . 3 3}$ \\
\hline 64.34 & 379.23 & & $\mathbf{3 7 1 . 8 3}$ \\
\hline $\mathbf{7 2}$ & $\mathbf{3 9 0 . 8 3}$ & $\mathbf{3 7 3 . 3 3}$ & $\mathbf{3 8 5 . 0 0}$ \\
\hline $\mathbf{9 6}$ & $\mathbf{4 0 7 . 5 0}$ & & \\
\hline
\end{tabular}

Table 4 shows the average gas production estimates obtained at each harvest time for some intermediate levels. For example, in vitro gas production for vegetative harvest time at 15 hours was found to be $266.02 \mathrm{ml} / 1 \mathrm{~g} \mathrm{DM}$.

Table 4. Average gas production estimates for some intermediate levels (ml/1 g DM)

\begin{tabular}{|c|l|l|l|}
\hline \multicolumn{4}{|c|}{ in vitro Gas Production (ml/1 g DM) } \\
\hline & & Harvest Times \\
\hline Hour & Vegetative & Flowering & Seeding Stages \\
\hline $\mathbf{3}$ & $\mathbf{1 3 7 . 5 0}$ & $\mathbf{1 1 6 . 6 7}$ & $\mathbf{1 1 3 . 3 3}$ \\
\hline $\mathbf{6}$ & $\mathbf{1 8 9 . 1 7}$ & $\mathbf{1 7 5 . 8 3}$ & $\mathbf{1 6 9 . 1 7}$ \\
\hline $\mathbf{1 2}$ & $\mathbf{2 4 1 . 6 7}$ & $\mathbf{2 2 1 . 6 7}$ & $\mathbf{2 1 6 . 1 7}$ \\
\hline 15 & 266.02 & 243.32 & 234.37 \\
\hline $\mathbf{2 4}$ & $\mathbf{3 0 6 . 6 7}$ & $\mathbf{2 8 6 . 6 7}$ & $\mathbf{2 7 1 . 6 7}$ \\
\hline 30 & 320.16 & 304.56 & 289.09 \\
\hline $\mathbf{4 8}$ & $\mathbf{3 5 0 . 8 3}$ & $\mathbf{3 4 0 . 8 3}$ & $\mathbf{3 2 6 . 6 7}$ \\
\hline 60 & 371.94 & 359.13 & 344.75 \\
\hline $\mathbf{7 2}$ & $\mathbf{3 9 0 . 8 3}$ & $\mathbf{3 7 3 . 3 3}$ & $\mathbf{3 5 8 . 3 3}$ \\
\hline 90 & 406.90 & 384.51 & 370.20 \\
\hline $\mathbf{9 6}$ & $\mathbf{4 0 7 . 5 0}$ & $\mathbf{3 8 5 . 0 0}$ & $\mathbf{3 7 1 . 8 3}$ \\
\hline
\end{tabular}


Intermediate level estimation could be made at each level of harvest time factor to obtain a desired gas production value. The table (Table 5) about this is given below. For example, 300 $(\mathrm{ml} / 1 \mathrm{~g} \mathrm{DM})$ in vitro gas production for harvest time vegetative is estimated to reach 21.83 hours.

Table 5. Intermediate level estimates that can be obtained for each level of harvest time for a desired gas production value (e.g. 300 (ml/1 g DM)

\begin{tabular}{|l|l|l|l|}
\hline \multicolumn{4}{|c|}{ in vitro Gas Production (ml/1 g DM) } \\
\hline & & \multicolumn{1}{|c|}{ Harvest Times } \\
\hline Hour & Vegetative & Flowering & Seeding Stages \\
\hline $\mathbf{3}$ & $\mathbf{1 3 7 . 5 0}$ & $\mathbf{1 1 6 . 6 7}$ & $\mathbf{1 1 3 . 3 3}$ \\
\hline $\mathbf{6}$ & $\mathbf{1 8 9 . 1 7}$ & $\mathbf{1 7 5 . 8 3}$ & $\mathbf{1 6 9 . 1 7}$ \\
\hline $\mathbf{1 2}$ & $\mathbf{2 4 1 . 6 7}$ & $\mathbf{2 2 1 . 6 7}$ & $\mathbf{2 1 6 . 1 7}$ \\
\hline 21.83 & 300 & & \\
\hline $\mathbf{2 4}$ & $\mathbf{3 0 6 . 6 7}$ & $\mathbf{2 8 6 . 6 7}$ & $\mathbf{2 7 1 . 6 7}$ \\
\hline 28.29 & & 300.00 & \\
\hline 34.47 & & & 300 \\
\hline $\mathbf{4 8}$ & $\mathbf{3 5 0 . 8 3}$ & $\mathbf{3 4 0 . 8 3}$ & $\mathbf{3 2 6 . 6 7}$ \\
\hline $\mathbf{7 2}$ & $\mathbf{3 9 0 . 8 3}$ & $\mathbf{3 7 3 . 3 3}$ & $\mathbf{3 5 8 . 3 3}$ \\
\hline $\mathbf{9 6}$ & $\mathbf{4 0 7 . 5 0}$ & $\mathbf{3 8 5 . 0 0}$ & $\mathbf{3 7 1 . 8 3}$ \\
\hline
\end{tabular}

The graph will be plotted within the range of the estimated time factor for each level of harvest time.

Figure 1 shows a graph of in vitro gas production values of different harvest times over time. Here the logarithm of the time was taken and drawing was made.

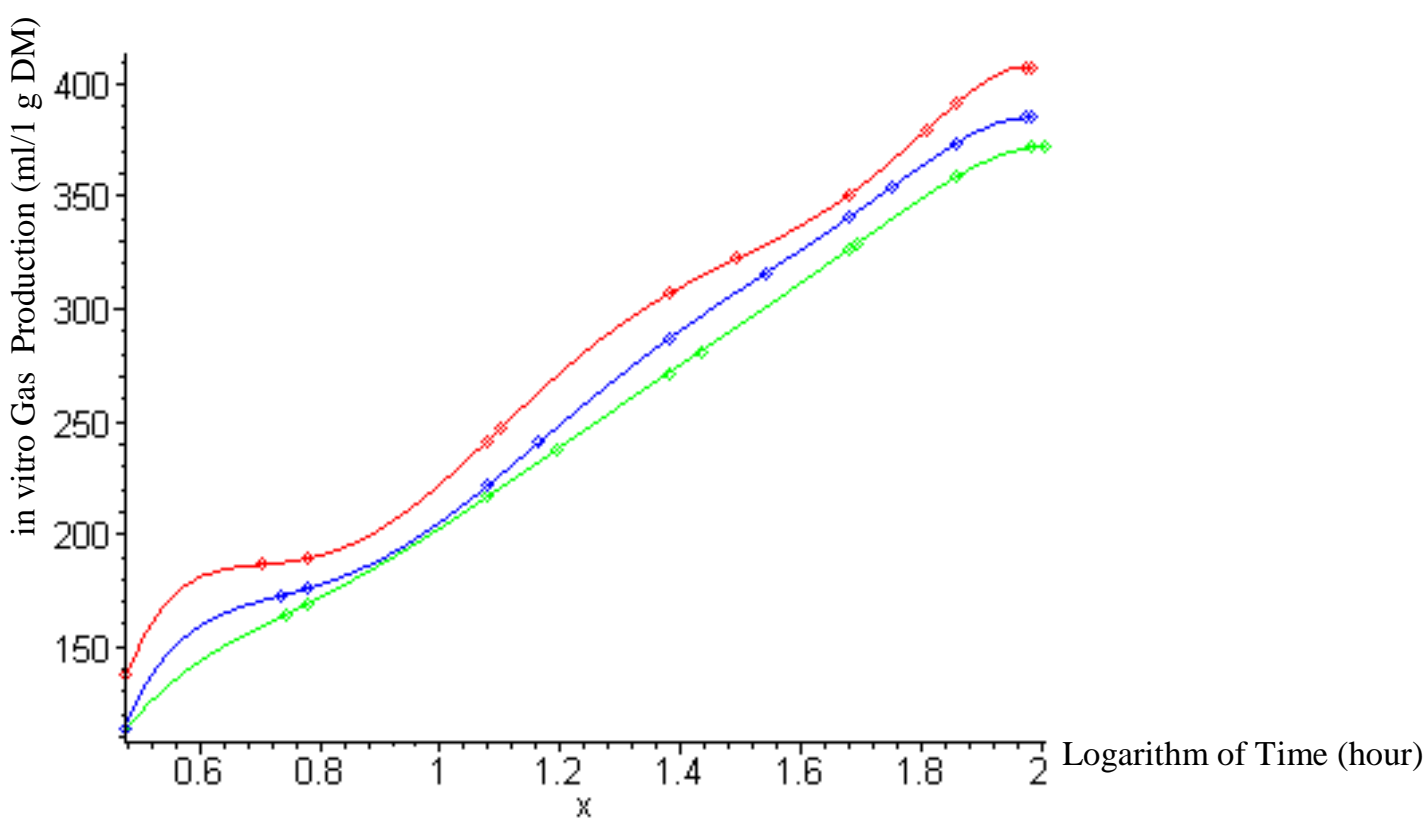

Figure 1. Vegetative $(\succ)$, Flowering $(\neg)(\log 3 \leq x \leq \log 96)$ and Seeding Stages ( $)(\log 3 \leq x \leq \log 102)$ for Lagrange interpolation 
Now the standard error can be written next to the average gas production value estimated so the standard error can be calculated. Özkan (2006) made the experiment in three iterations and Table 1 was generated by using the average in vitro gas production amount. Therefore, the standard error table obtained by using Lagrange interpolation is as follows (Table 6). For example, the standard errors of values of extremum and turning points (407.61 ve $186.58 \mathrm{ml} / 1$ g DM) estimated at 94.32 and 5.04 hours, respectively for harvest time vegetative were also estimated as 2.28 and $4.20 \mathrm{ml} / 1 \mathrm{~g} \mathrm{DM}$, respectively (Table 6 and 7). In addition, the standard error of in vitro gas production (266.02 ml/1 g DM) estimated at 15 hours for harvest time vegetative was estimated as $2.50 \mathrm{ml} / 1 \mathrm{~g}$ DM (Table 8 ).

Table 6. Intermediate levels with extremum points and the standard error estimates of their in vitro gas production (ml/1 g DM)

\begin{tabular}{|l|l|l|l|}
\hline \multicolumn{5}{|c|}{ Standard Error Estimates of in vitro Gas Production (ml/1 g DM) } \\
\hline & \multicolumn{3}{|c|}{ Harvest Times } \\
\hline Hour & Vegetative & Flowering & Seeding Stages \\
\hline $\mathbf{3}$ & $\mathbf{2 . 8 9}$ & $\mathbf{2 . 2 0}$ & $\mathbf{2 . 2 0}$ \\
\hline $\mathbf{6}$ & $\mathbf{4 . 6 4}$ & $\mathbf{3 . 6 3}$ & $\mathbf{1 . 6 7}$ \\
\hline $\mathbf{1 2}$ & $\mathbf{3 . 0 0}$ & $\mathbf{2 . 2 0}$ & $\mathbf{4 . 4 1}$ \\
\hline $\mathbf{2 4}$ & $\mathbf{3 . 0 0}$ & $\mathbf{3 . 0 0}$ & $\mathbf{3 . 0 0}$ \\
\hline $\mathbf{4 8}$ & $\mathbf{3 . 6 3}$ & $\mathbf{3 . 0 0}$ & $\mathbf{4 . 4 1}$ \\
\hline $\mathbf{7 2}$ & $\mathbf{1 . 6 7}$ & $\mathbf{2 . 2 0}$ & $\mathbf{4 . 6 4}$ \\
\hline 94.32 & 2.28 & & \\
\hline 94.69 & & 4.11 & \\
\hline $\mathbf{9 6}$ & $\mathbf{2 . 5}$ & $\mathbf{4 . 3 3}$ & $\mathbf{2 . 2 4}$ \\
\hline 101.33 & & & 1.42 \\
\hline
\end{tabular}

Table 7. Intermediate levels with turning points and the standard error estimates of their in vitro gas production (ml/1 g DM)

\begin{tabular}{|l|l|l|l|}
\hline \multicolumn{5}{|c|}{ Standard Error Estimates of in vitro Gas Production (ml/1 g DM) } \\
\hline & \multicolumn{3}{|c|}{ Harvest Times } \\
\hline Hour & Vegetative & Flowering & Seeding Stages \\
\hline $\mathbf{3}$ & $\mathbf{2 . 8 9}$ & $\mathbf{2 . 2 0}$ & $\mathbf{2 . 2 0}$ \\
\hline 5.04 & 4.20 & & \\
\hline 5.36 & & 3.78 & \\
\hline 5.52 & & & 0.94 \\
\hline $\mathbf{6}$ & $\mathbf{4 . 6 4}$ & $\mathbf{3 . 6 3}$ & $\mathbf{1 . 6 7}$ \\
\hline $\mathbf{1 2}$ & $\mathbf{3 . 0 0}$ & $\mathbf{2 . 2 0}$ & $\mathbf{4 . 4 1}$ \\
\hline 12.54 & 2.87 & & \\
\hline 14.59 & & 2.18 & \\
\hline 15.68 & & & 3.86 \\
\hline $\mathbf{2 4}$ & $\mathbf{3 . 0 0}$ & $\mathbf{3 . 0 0}$ & $\mathbf{3 . 0 0}$ \\
\hline 27.14 & & & 3.00 \\
\hline 31.19 & 3.73 & & \\
\hline 34.89 & & 3.45 & $\mathbf{4 . 4 1}$ \\
\hline $\mathbf{4 8}$ & $\mathbf{3 . 6 3}$ & $\mathbf{3 . 0 0}$ & 4.49 \\
\hline 49.32 & & & \\
\hline 56.26 & & 2.57 & $\mathbf{4 . 6 4}$ \\
\hline 64.34 & 2.21 & & $\mathbf{2 . 2 4}$ \\
\hline $\mathbf{7 2}$ & $\mathbf{1 . 6 7}$ & $\mathbf{2 . 2 0}$ & \\
\hline $\mathbf{9 6}$ & $\mathbf{2 . 5}$ & $\mathbf{4 . 3 3}$ & \\
\hline
\end{tabular}


Table 8. Standard error estimates of average in vitro gas production amount for some intermediate levels (ml/1 g DM)

\begin{tabular}{|c|l|l|l|}
\hline \multicolumn{4}{|c|}{ Standard Error Estimates of in vitro Gas Production (ml/1 g DM) } \\
\hline & \multicolumn{3}{|c|}{ Harvest Times } \\
\hline Hour & Vegetative & Flowering & Seeding Stages \\
\hline $\mathbf{3}$ & $\mathbf{2 . 8 9}$ & $\mathbf{2 . 2 0}$ & $\mathbf{2 . 2 0}$ \\
\hline $\mathbf{6}$ & $\mathbf{4 . 6 4}$ & $\mathbf{3 . 6 3}$ & $\mathbf{1 . 6 7}$ \\
\hline $\mathbf{1 2}$ & $\mathbf{3 . 0 0}$ & $\mathbf{2 . 2 0}$ & $\mathbf{4 . 4 1}$ \\
\hline 15 & 2.50 & 2.20 & 3.97 \\
\hline $\mathbf{2 4}$ & $\mathbf{3 . 0 0}$ & $\mathbf{3 . 0 0}$ & $\mathbf{3 . 0 0}$ \\
\hline 30 & 3.63 & 3.37 & 3.09 \\
\hline $\mathbf{4 8}$ & $\mathbf{3 . 6 3}$ & $\mathbf{3 . 0 1}$ & $\mathbf{4 . 4 1}$ \\
\hline 60 & 2.59 & 2.40 & 4.87 \\
\hline $\mathbf{7 2}$ & $\mathbf{1 . 6 7}$ & $\mathbf{2 . 2 1}$ & $\mathbf{4 . 6 4}$ \\
\hline 90 & 1.83 & 3.42 & 3.05 \\
\hline $\mathbf{9 6}$ & $\mathbf{2 . 5}$ & $\mathbf{4 . 3 3}$ & $\mathbf{2 . 2 4}$ \\
\hline
\end{tabular}

Table 9. Intermediate level standard error time estimates for each level of harvest time for a desired gas production amount (300 ml/1 g DM)

\begin{tabular}{|l|l|l|l|}
\hline \multicolumn{5}{|c|}{ Standard Error Estimates of in vitro Gas Production (ml/1 g DM) } \\
\hline & \multicolumn{3}{|c|}{ Harvest Times } \\
\hline Hour & Vegetative & Flowering & Seeding Stages \\
\hline 3 & $\mathbf{2 . 8 9}$ & 2.20 & $\mathbf{2 . 2 0}$ \\
\hline $\mathbf{6}$ & $\mathbf{4 . 6 4}$ & $\mathbf{3 . 6 3}$ & $\mathbf{1 . 6 7}$ \\
\hline 12 & $\mathbf{3 . 0 0}$ & $\mathbf{2 . 2 0}$ & $\mathbf{4 . 4 1}$ \\
\hline 21.83 & 2.76 & & \\
\hline $\mathbf{2 4}$ & $\mathbf{3 . 0 0}$ & $\mathbf{3 . 0 0}$ & $\mathbf{3 . 0 0}$ \\
\hline 28.29 & & 3.30 & \\
\hline 34.47 & & & 3.37 \\
\hline $\mathbf{4 8}$ & $\mathbf{3 . 6 3}$ & $\mathbf{3 . 0 0}$ & $\mathbf{4 . 4 1}$ \\
\hline $\mathbf{7 2}$ & $\mathbf{1 . 6 7}$ & $\mathbf{2 . 2 0}$ & $\mathbf{4 . 6 4}$ \\
\hline $\mathbf{9 6}$ & $\mathbf{2 . 5}$ & $\mathbf{4 . 3 3}$ & $\mathbf{2 . 2 4}$ \\
\hline
\end{tabular}

The standard error values in the last table above (Table 9) are the standard error values of the desired average result amount (300 ml/1 g DM). For example, for vegetative, the first level of harvesting time, the standard error would be estimated as $2.76 \mathrm{ml} / 1 \mathrm{~g} \mathrm{DM}$ when the average hour was 21.83 hours. This means that; If the average hour is 21.83 hours, in vitro gas production is estimated to be $300 \mp 2.76$ with $68 \%$ probability.

The graphs showing the variation of each harvest time below are drawn to include 95\% significance level confidence limits (Figures 2,3 and 4). 


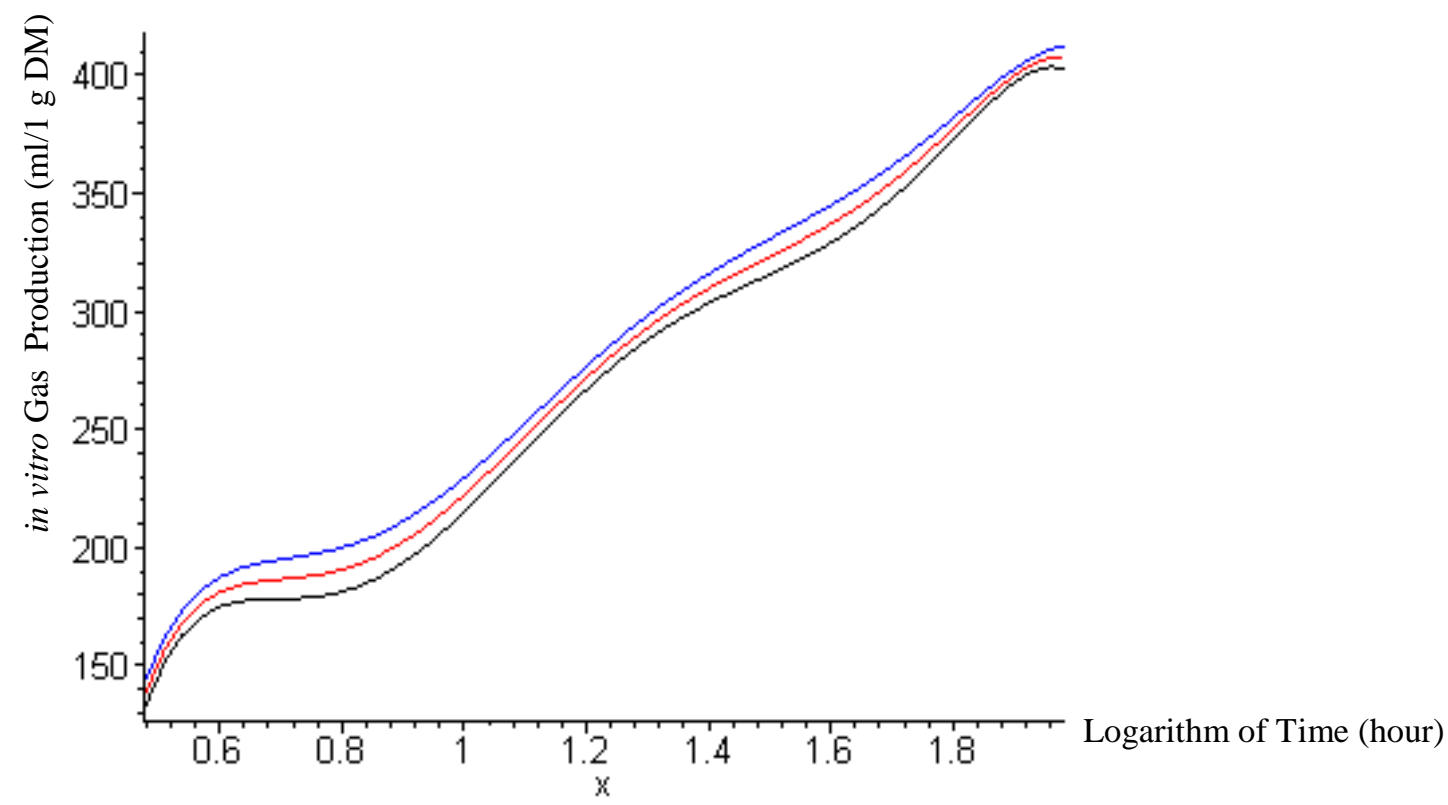

Figure 2. Confidence limits with Lagrange interpolation for harvest time (vegetative) $(\log 3 \leq x \leq \log 96)$

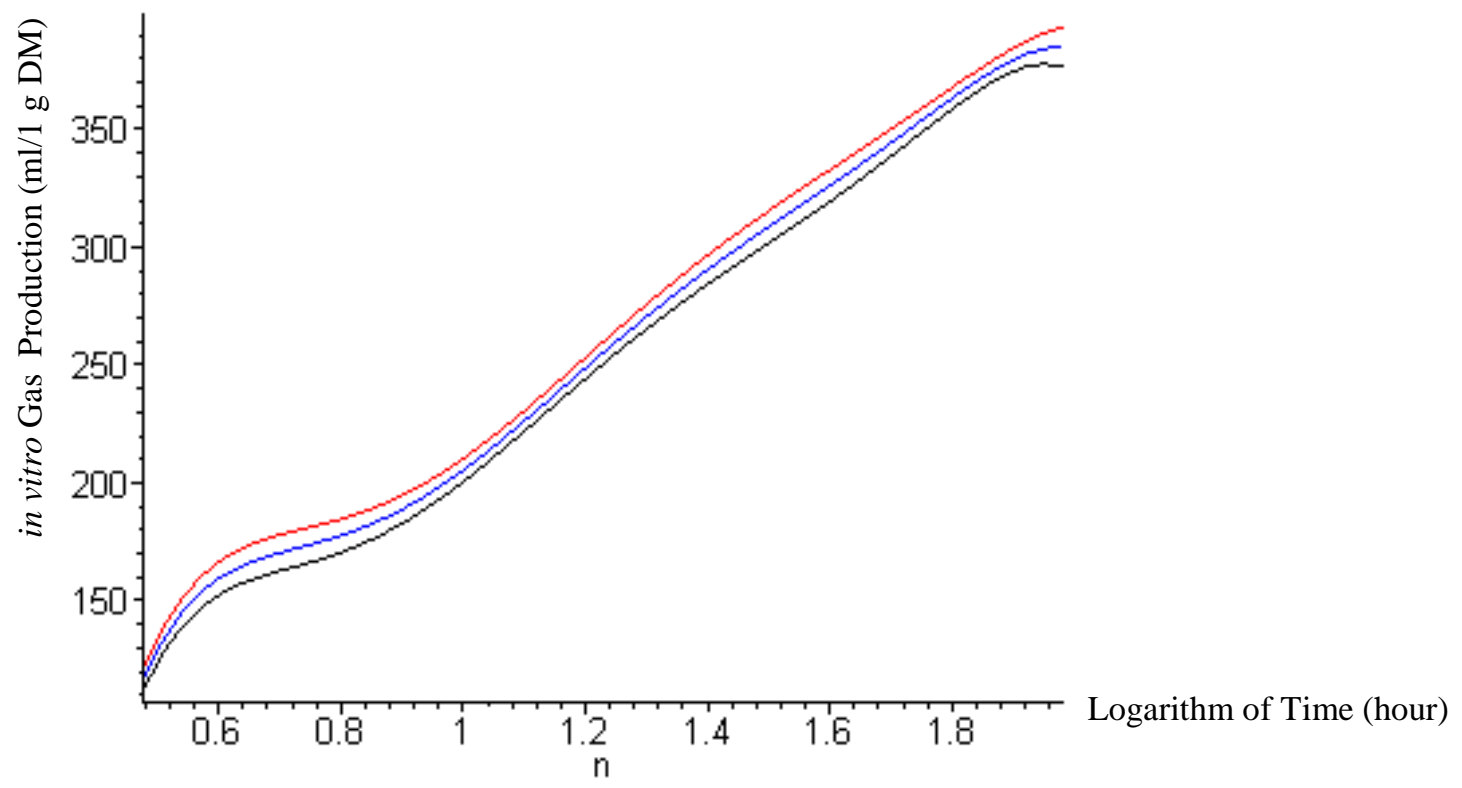

Figure 3. Confidence limits with Lagrange interpolation for harvest time (flowering) $(\log 3 \leq x \leq \log 96)$ 


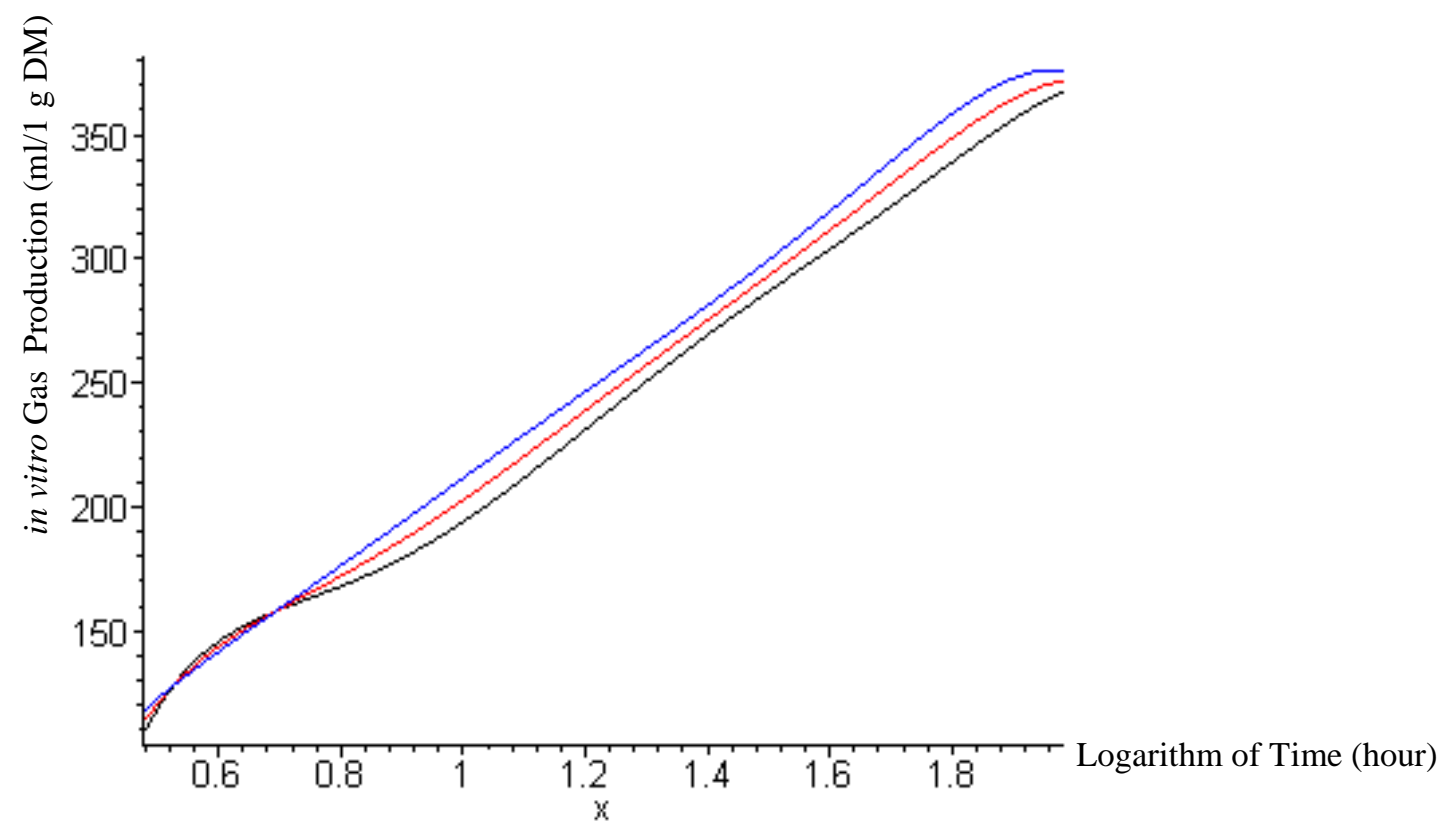

Figure 4. Confidence limits with Lagrange interpolation for harvest time (seeding stages) $(\log 3 \leq x \leq \log 96)$

According to the interpolation study, for example although there is not a transition time that would make the average of 3 hours and 6 hours the same with 5\% error rate, at 95\% significance level 3.285904602 and 3.921851446 were found to be the same at the 3rd hour and the 6th hour, respectively. In addition, the averages of only 72 hours and 96 hours were the same with 5\% error rate. Since the harvest time factor levels are discrete, interpolation cannot be performed.

In addition, by checking all levels of the other factor or the desired intermediate levels for a desired level or even intermediate level of a factor, it can also be checked whether there is a statistically significant difference according to significance levels and if so, it can also be checked where this difference begins. In this context, for the first harvest time (vegetative), all levels of the other factor were checked and a statistically significant difference was found among all means at 95\% significance level. For example, although there is no transition time to make the average of 3 hours and 6 hours the same with error rate, at 95\% significance level 3.124320994 and 3.640861685 were found to be the same at the 3rd hour and the 6th hour, respectively. Furthermore, for example although there is no transition time to make the average of 72 hours and 96 hours the same with error rate, at 95\% significance level 76.98658687 and 79.31688265 were found to be the same at the 72nd hour and the 96th hour, respectively

Now the missing observation analysis will be performed by Lagrange interpolation. For this purpose, we assume that the measurements of 24 hours, 48 hours and 72 hours of Trifolium repens, one of the legume forage plants, for the harvest time factors, vegetative, flowering and seeding stages, respectively are missing observations in in vitro gas production. The estimated missing observations will be given in Table 10. 
Table 10. In vitro gas production and standard error estimates according to the levels of some missing observation hours (24 hours, 48 hours and 72 hours) (ml/1 g DM)

\begin{tabular}{|c|l|l|l|}
\hline \multicolumn{4}{|c|}{ in vitro Gas Production and Standard Error (ml/1 g DM) } \\
\hline \multicolumn{3}{|c|}{ Harvest Times } \\
\hline Hour & Vegetative & Flowering & Seeding Stages \\
\hline 3 & 137.50 & 116.67 & 113.33 \\
\hline 6 & 189.17 & 175.83 & $\mathbf{1 6 9 . 1 7}$ \\
\hline 12 & 241.67 & 221.67 & 216.17 \\
\hline 24 & $306.67 \mp 3.00$ & 286.67 & 271.67 \\
& $287.37 \mp 4.84$ & & \\
\hline 48 & 350.83 & $340.83 \mp 3.00$ & 326.67 \\
& & $349.04 \mp 2.43$ & \\
\hline 72 & 390.83 & 373.33 & $358.33 \mp 4.64$ \\
& & & $354.38 \mp 5.36$ \\
\hline 96 & 407.50 & 385.00 & 371.83 \\
\hline
\end{tabular}

In Table 10, the missing observation estimates are given with the standard error. In vegetative, the estimated missing observation value for 24 hours was statistically different at 95\% significance level. Moreover, in flowering, the estimated missing observation value for 48 hours was not statistically different at the same significance level. In addition, in seeding stages, the estimated missing observation value for 72 hours was statistically same at $68 \%$ significance level.

\section{Conclusion}

In addition to the well-known classical analysis, by using Lagrange interpolation it is possible to create the estimates of the intermediate levels for the in vitro gas production: extremum points, turning points, the average estimated values of in vitro gas production for a desired intermediate value, the estimated intermediate values for a desired in vitro gas production of each harvest time, standard errors of all estimated values, the graphs of the confidence limits for each harvest time, in vitro gas production and standard error estimates according to the levels of some missing observation hours (24 hours, 48 hours and 72 hours).

\section{Acknowledge}

This study is produced from Mehmet Korkmaz’s PhD. Thesis (No:252541).

\section{References}

[1] Bayram, M., Fen ve mühendislik için nümerik analiz, Aktif yayınevi, Istanbul, (2002).

[2] Korkmaz, M. and Efe, E., "The solution of Lagrange interpolation approaches with maple 6 on the experimental data”, ARPN Journal of Science and Technology, 3 (5) (2013) : 492-511.

[3] Bek, Y.,Efe, E., Araştırma ve deneme netodları I, Ç.Ü. Ziraat Fakültesi,Yay.No: 71, Adana (1988). 
[4] Efe, E., Bek, Y., Şahin, M., SPSS’te çözümleri ile istatistik yöntemler II, Kahramanmaraş Sütçü İmam Üniversitesi Rektörlüğü Yayın No: 73, Ders Kitapları Yayın No: 9, K.S.Ü. Basımevi, Kahramanmaraş (2000).

[5] Orhan, H., Efe, E., Şahin, M. SAS yazılımı ile istatistiksel analizler, Tuğra Ofset, Isparta (2004).

[6] Korkmaz, M., Deneysel verilere bazı interpolasyon yaklaşımları üzerine bir çalışma, Kahramanmaraş Sütçü İmam Üniversitesi, Fen Bilimleri Enstitüsü, Kahramanmaraş (PhD.Thesis) (2009).

[7] Korkmaz, M. and Efe, "Lagrange interpolation approach to experimental data”, Bulletin of Pre and Applied science, volume 31E (Math \& Stat.), Issue (No.2) E. (2012) : 181191.

[8] Özkan, Ç.Ö., Farklı dönemlerde hasat edilen bazı baklagil yem bitkilerinin sindirim derecesinin ve metabolik enerji değerlerinin in vitro gaz tekniği ile belirlenmesi, Kahramanmaraş Sütçü İmam Üniversitesi, Fen Bilimleri Enstitüsü, Kahramanmaraş (MSc.Thesis). (2006).

[9] Türker, E.S., Can, E., Bilgisayar uygulamalı sayısal analiz yöntemleri, Değişim Yayınları No: 9 ( II.Bask1 ), Adapazarı, (1997).

[10] Çağal, B., Sayısal Analiz, Birsen yayınları, İstanbul, s. 97-98 (2000).

[11] Amirali, G., Duru, H. Nümerik analiz, Pegem A Yayıncılık, Ankara, (2002). 